INDO GLOBAL JOURNAL OF

PHARMACEUTICAL SCIENCES

ISSN 2249- 1023

\title{
A Review on Biosimilars of Filgrastim, a Recombinant Granulocyte Stimulating Factor (G-CSF): Results from Clinical Studies
}

\author{
Purnam Hoshe Ruba, Mehak Aggarwal, Pragya Vats, Shweta Dang * \\ Jaypee Institute of Information Technology, Sector-62, Noida-201307, UP, India
}

Address for Correspondance: Shweta Dang, shweta.dang@jiiit.ac.in

Keywords

Biosimilar;

Filgrastim; G-CSF;

Neutropenia.

\begin{abstract}
It has been widely reported by various publications that biosimilars are safe, effective and are available at lower prices than the biological medical products. Thus these can also be given to cancer patients undergoing chemotherapy. Filgrastim is a recombinant granulocyte stimulating factor (G-CSF) which promotes the growth, proliferation, differentiation, and maturation of neutrophil precursors and thus is used to treat neutropenia. Due to the high costs of these biologics, biosimilars have been introduced. Biosimilars are the copies of the biopharmaceuticals which are manufactured using alternate methods. These can be produced by different manufacturers when the biological medical products go off patent. Neupogen ${ }^{\circledR}$ is an FDA approved biological medical product manufactured by Amgen for which many biosimilars have been approved by the European Medicines Agency (Ratiograstim $\AA$, Tevagrastim $\AA$, Biograstim $\AA$, Zarzio $\AA$, Nivestim $\AA$ ). The focus of this study is to review the clinical studies done to assess the safety and effectiveness of the Biosimilars of Neupogen in chemotherapy-induced neutropenia in cancer patients. The biosimilars taken into study are Tevagrastim ${ }^{\circledR}$, Zarzio ${ }^{\circledR}$, Nivestim ${ }^{\circledR}$ and Pegfilgrastim ${ }^{\circledR}$. Different studies like single dose, randomized, assessor-blinded, 2-way crossover study, observational, prospective, longitudinal, and multicentric study and single center, open label, randomized trial were conducted on group of people receiving biosimilars from different manufacturers. Parameters like peak concentration $\left(\mathrm{C}_{\max }\right)$, area under the curve $\left(\mathrm{AUC}_{\mathrm{t}}\right)$, absolute neutrophil count $(\mathrm{ANC}), \mathrm{AUEC}_{\mathrm{t}}, \mathrm{E}_{\max }, \mathrm{AUC}_{\mathrm{inf}}, \mathrm{T}_{\max }, \mathrm{t}_{\text {half }}$ were calculated to confirm the similarity between the proposed biosimilar and the reference product. According to PK/PD studies, no significant differences were observed and thus the biosimilars were proved to be highly similar to the reference product. (C) 2016 iGlobal Research and Publishing Foundation. All rights reserved.
\end{abstract}

Conference Proceedings: International Conference on Advances in Plant and Microbial Biotechnology (PMB2017); JIIT, Noida: February 02-04, 2017

Indo Global Journal of Pharmaceutical Sciences( ISSN 22491023 ; CODEN- IGJPAI; NLM ID: 101610675) indexed and abstracted in EMBASE(Elsevier), SCIRUS(Elsevier),CABI, CAB Abstracts, Chemical Abstract Services(CAS), American Chemical Society(ACS), Index Copernicus, EBSCO, DOAJ, Google Scholar and many more. For further details, visit http://iglobaljournal.com 